\title{
Impact of the Cognitive Status on the Memory Complaints in MS Patients
}

\author{
M. Demers, I. Rouleau, P. Scherzer, J. Ouellet, C. Jobin, P. Duquette
}

\begin{abstract}
Objective: Despite the evidence of cognitive deficits in Multiple Sclerosis (MS) patients, evaluation of their cognitive integrity is often limited to the use of clinical interviews and questionnaires. However, the consensus in the literature is that these patients under- or overestimate their deficits and repercussions. The objective of this study was to clarify why some patients overestimate while others underestimate their memory deficits. Method: Fifty-four participants (30 MS, 24 controls) completed the Prospective and Retrospective Memory Questionnaire (PRMQ) and were tested on a battery of neuropsychological tests. Based on the test results, MS patients were categorized as having either mild or moderate/severe cognitive deficits. Results: The moderate/severe MS group differed from the two other groups on the Rey Auditory Verbal Learning Test (RAVLT) but did not differ from the control group on the PRMQ. Conversely, the mild MS group did not differ from the control group on the RAVLT but did report significantly more problems than this group on the PRMQ. There was no difference between the two clinical groups on the Depression Index (Beck) but there was a significant correlation $(\mathrm{r}=.409)$ between the depression scores and the overestimation of prospective memory problems (PRMQ). Conclusion: The results explain the contradiction in the literature. It is the mild group who overestimates, maybe because they are overly concerned by their deficits, whereas the cognitive impairments of the moderate/severe group lead them to underestimate and may make their selfassessment unreliable. Formal testing or information from a significant other would be advisable.
\end{abstract}

RÉSUMÉ: Objectifs: Bien que l'existence de troubles cognitifs chez les patients avec SEP soit reconnue, l'évaluation du fonctionnement cognitif est souvent limitée à l'entrevue clinique et à l'administration de questionnaires. Méthode : Cinquante-quatre participants (30 SEP, 24 témoins) ont complétée le «Prospective and Retrospective Memory Questionnaire» (PRMQ) ainsi qu'une batterie de tests neuropsychologiques. Les résultats obtenus à cette batterie de tests ont servi à classifier les patients selon la sévérité de leur atteinte cognitive (légère et modérée/sévère). Résultats : Le groupe de patients avec atteinte modérée/sévère se distingue des deux autres groupes à l'épreuve d'apprentissage des 15 mots de Rey mais ne diffère pas du groupe témoin sur le PRMQ. En revanche, le groupe de patients avec atteinte cognitive légère ne diffère pas du groupe témoin sur le RAVTL mais rapporte significativement plus de troubles de mémoire au PRMQ. Il n'y a pas de différence entre les deux groupes clinique sur l'index de dépression (Beck) mais il existe une corrélation significative $(\mathrm{r}=409)$ entre les scores de dépression et la surestimation des troubles de mémoire prospective au PRMQ. Conclusion : Ces résultats expliquent la contradiction apparente rapportée dans la littérature. En effet, les patients avec atteinte cognitive légère surestiment leurs déficits, peut-être en raison de leur inquiétude, alors que les patients du groupe avec atteinte modérée/sévère sous-estiment leurs déficits et pourraient ne pas être de bons juges de leur fonctionnement cognitif réel. Dans ces cas, il serait souhaitable de procéder à une évaluation formelle ou à la collecte d'informations chez des proches.

Can. J. Neurol. Sci. 2011; 38: 728-733

It is now well-established that cognitive assessment is important in the evaluation of patients with multiple sclerosis (MS). Cognitive deficits, which have been reported in up to $60 \%$ of the patients, may be totally independent of the sensori-motor signs often associated with MS and may have profound consequences on daily life activities of the individual with MS and their close relatives. ${ }^{1-6}$

Although the cognitive profiles noted in patients with MS may vary, there are a number of cognitive domains that are more sensitive to brain lesions associated with MS. Deficits in episodic memory, working memory, speed of information processing, attention and executive functions have been repeatedly found in patients with MS. ${ }^{2,7-9}$

In studies of episodic memory in MS, most authors were interested in retrospective memory that is, recalling or recognizing previous information, events, conversation, etc. However, despite frequent complaints concerning prospective memory, that is difficulties in carrying out an intended action at the appropriate moment, such as not forgetting to pick up the dry-cleaning while driving home after work, it is rarely assessed in neuropsychological testing. The few studies of prospective memory in MS have confirmed the vulnerability of this memory ability in this population. ${ }^{10-12}$

In most MS clinics, formal neuropsychological testing is not offered to all patients, only to those whose cognitive deficits may have an impact on their work or their functional autonomy. The assessment of cognitive integrity is usually determined

From the Département de psychologie (MD, IR, PS) and Institut des sciences cognitives, Université du Québec à Montréal, UQAM; MS Clinic (IR, PD), Centre Hospitalier de l'Université de Montréal; Institut de Réadaptation Gingras-Lindsay de Montréal (JD); Hôpital du Sacré-Coeur (CJ), Montréal, Quebec, Canada.

Received January 17, 2011. Final Revisions SubmitTed March 18, 2011. Correspondence to: Isabelle Rouleau, Département de psychologie, Université du Québec à Montréal, CP 8888, Succ. Centre-ville, Montréal, QC, H3C 3P8, Canada. 
using a clinical interview and questionnaires. However, a number of studies have shown that there is a discrepancy between perception and reality. Some authors found that MS patients tend to consistently overestimate their cognitive problems, ${ }^{13}$ while others found that up to one third of their MS patients tend to underestimate their cognitive deficits. ${ }^{14}$ This contradiction in the results might be related to the cognitive status of the MS patients, enrolled in these studies.

The goal of this study was to examine the subjective appraisal of prospective and retrospective memory functioning in MS patients, taking into account their cognitive impairment status determined by their performance on various neuropsychological tests. ${ }^{6}$ Subjective evaluations were carried out using the Prospective and Retrospective Memory Questionnaire (PRMQ) originally developed ${ }^{15}$ for the study of Alzheimer's disease patients. A second objective was to compare the subjective evaluation of memory functioning in patients with $\mathrm{MS}$ to population norms. In addition, since the frontal lobe semiology often observed in MS patients could interfere with their subjective evaluation, tests sensitive to executive dysfunction were also administered. ${ }^{14,16,17}$ We expected that MS patients with moderate to severe cognitive impairments would tend to underestimate their memory deficits. This problem of estimation is postulated to be related to the severity of their cognitive impairments, which would affect judgement of their abilities, particularly when a frontal lobe semiology is present. On the other hand, we expected that MS patients without cognitive impairment, but with depressive symptoms, would tend to overestimate their memory deficits.

\section{MeTHODS \\ Participants}

Thirty (30) patients with MS and 24 control subjects matched for age and education participated in this study. The demographic data are presented in Table 1. For the MS group, the participants were included if they satisfied MacDonald's criteria. $^{18}$ Expanded Disability Status Scale (EDSS) scores ranged from 0 to $7.5 .^{19}$ Patients were recruited through the MS Clinic of the Centre Hospitalier de l'Université de Montréal. They were excluded if they a) had severe motor, visual or hearing impairment that might interfere with cognitive testing, b) had a history of drug abuse or had a nervous system disorder other than MS, or c) were not clinically stable, i.e. did experience a relapse in the last month. Control participants were recruited through MS patients, personal contacts and notices on the university and hospital bulletin boards. They were excluded if they had a history of drug abuse, psychiatric illness, head injury or other neurological problems. All subjects were recruited on a voluntary basis and their first language was French. The research project was formally approved by the ethics committees of the Centre Hospitalier de l'Université de Montréal and all subjects signed an informed consent.

Multiple sclerosis patients were classified for the severity of their cognitive impairment as determined by the number of tests failed (i.e. performance at or below the fifth percentile of the control group) (0-3 tests failed = mild; 4-6 tests failed = moderate; $7+$ tests failed $=$ severe $)$. This classification was based on the same general procedure described by Rao et al.

Table 1: Demographic characteristics of participants (MS with mild or moderate/severe cognitive deficit and Controls) Mean (standard deviation)

\begin{tabular}{|c|c|c|c|c|}
\hline & $\begin{array}{c}\text { MS mild } \\
(0-3 \text { tests failed }) \\
n=14\end{array}$ & $\begin{array}{l}\text { MS Moderate/Severe } \\
\qquad \begin{array}{c}(4+\text { tests failed }) \\
n=16\end{array}\end{array}$ & $\begin{array}{l}\text { Controls } \\
n=24\end{array}$ & $\begin{array}{c}P \\
\text { F or } \chi^{2}\end{array}$ \\
\hline Gender $\mathrm{M} / \mathrm{F}$ & $6 / 8$ & $4 / 12$ & $10 / 14$ & ns \\
\hline Age & $45.9(7.5)$ & $44.3(8.5)$ & $45.0(10.1)$ & ns \\
\hline Education & $14.1(2.3)$ & $13.2(2.6)$ & $13.2(2.3)$ & $\mathrm{ns}$ \\
\hline EDSS & $3.5(2.6)$ & $4.4(2.7)$ & - & ns \\
\hline $\begin{array}{c}\text { Time since diagnosis } \\
\text { (years) }\end{array}$ & $6.64(5.8)$ & $12.6(8.5)$ & - & .038 \\
\hline $\begin{array}{c}\text { Disease duration } \\
\text { (years) }\end{array}$ & $14.3(9.3)$ & $18.7(10.5)$ & - & ns \\
\hline $\begin{array}{c}\text { Disease course* } \\
\text { (RRMS/SPMS/PPMS) }\end{array}$ & $8 / 3 / 3$ & $7 / 7 / 2$ & - & ns \\
\hline
\end{tabular}

* RRMS: relapsing-remitting MS; SPMS: secondary progressive MS; PPMS: primary progressive MS 
where the total number of patients who performed at or below the fifth percentile of the control group was calculated for each of the nine neuropsychological measures. ${ }^{6,20}$ Seven measures were individual scores from a neuropsychological test, whereas two were composite scores, namely executive functions and concept formation/reasoning. Composite scores for these cognitive functions were used to avoid overrepresentation of these functions, since they consisted respectively of four and five tests, as opposed to one or two tests for the other measures. Based on the criterion of the number of tests failed, 14 MS patients were classified as mildly impaired, 10 as moderately impaired and 6 as severely impaired.

\section{Test battery}

\section{Prospective and Retrospective Memory Questionnaire ${ }^{15}$ :}

The $P R M Q$ is composed of 16 questions assessing the frequency of everyday memory errors on a five-point scale (1: never, 2: rarely, 3: sometimes, 4: often, 5 : very often). Half of the questions concern prospective memory and half concern retrospective memory. The questionnaire also takes into account retention time (half short-term, half long-term) and whether or not relevant cues are available to prompt remembering an event or an action (half self-generated cues, half environmental cues). Thus, there are two questions for each of the eight categories. For example, the question Do you forget something that you were told a few minutes before? falls into the retrospective short-term self-cued category, whereas Do you fail to mention or to give something to a visitor that you were asked to pass on? falls into the prospective long-term environmentally-cued category. The higher the score, the more frequent memory errors were reported.

\section{Neuropsychological tests}

All MS patients and 10 of the 24 control participants were evaluated using a comprehensive battery of neuropsychological tests: retrospective memory (Rey Auditory Verbal Learning Test RAVLT); executive functions (Pictures arrangement- $P A$, (WAIS-III) Mazes (WISC-III), Similarities (WAIS-III), Stroop, Trail Making Test - TMT, Wisconsin Card Sorting Test - WCST, Zoo Map [BADS]); language (Verbal Fluency); working memory (Paced Auditory Serial Addition Test - PASAT) and tests of perceptual (Bell cancellation test) and constructive abilities (Clock drawing test). Tests of theory of mind (social cognition) were also administered and the results are reported elsewhere. ${ }^{20}$ This exhaustive battery was preferred to the shorter screening batteries commonly used in patients with MS because it covers more thoroughly the most relevant cognitive functions known to be affected in MS, with special attention to executive functions. Because of the large number of variables produced by the neuropsychological evaluation, composite scores were computed: a memory score (mean of $\mathrm{z}$ scores obtained in the RAVLT:) and an executive function score (mean of $\mathrm{z}$ scores obtained in WCST, TMT, Mazes, Stroop, PA, Similarities, Zoo Map). Depression was evaluated using the Beck Depression Inventory $(B D I) .^{21}$

\section{Procedures}

All participants were tested individually in a university laboratory at the Université du Québec à Montréal, or in their own home, as long as it was a quiet environment. Most participants were assessed during three 90 -minute sessions. The neuropsychological tests and the questionnaire were administered in the same fixed order for all participants.

\section{Data Analysis}

Analyses of variance (ANOVAs) (with repeated measures when it was appropriate) were performed to compare groups on the different measures ( $P R M Q$, neuropsychological tests, $B D I$ ). When a significant result was detected, post-hoc Tukey analysis was added to explore and specify the differences observed. The effect size correlation (Rosenthal: r) was also computed by first measuring the Cohen's $d$. The significant level was set at 0.05 (two-tailed). The SPSS (v. 17.0) statistical program was used for these analyses.

\section{RESULTS}

PRMQ: The mean of the scores of the two questions was computed for each of the eight $P R M Q$ categories. In addition, a mean score was computed for the prospective memory (PM) errors (mean of the four PM categories) and for the retrospective memory (RM) errors (mean of the four RM categories).

Analyses of variance were employed to determine whether MS patients differed significantly from control subjects. As expected, MS patients reported PM errors more frequently than control subjects $(\mathrm{F}[1,52]=9.77, \mathrm{p}=.003 ; r=.40)$, a tendency that was also noted for RM errors $(F[1,52]=3.57, \mathrm{p}=.065 ; \mathrm{r}=$ .25). In addition, PM errors were reported more often than RM errors $(\mathrm{F}[1,52]=26.81, \mathrm{p}<.001 ; r=.33)$ but the Group $\mathrm{X}$ Condition (PM, RM) interaction failed to reach significance ( $F$ $[1,52]=3.21, \mathrm{p}=.079 ; r=.06)$, suggesting that although PM deficits were more frequently reported than RM deficits, this was not specific to MS patients. Finally, among the eight categories of errors, three reached significance (MS vs. NC: $\mathrm{p}<.05 ; r$ between .31 and .45 ), all related to prospective memory failures.

Additional analyses (ANOVAs) were performed using the level of cognitive impairment (established using Rao's criterion) as an independent variable. Because of the small sample size, MS groups with moderate $(\mathrm{N}=10)$ and severe $(\mathrm{N}=6)$ cognitive impairment were combined for these analyses. There was a significant difference between the groups (mild, moderatesevere, control) in their report of PM errors, $(\mathrm{F}[2,51]=8.21, \mathrm{p}$ $=.001 ; r=.49)$ and $\mathrm{RM}$ errors $(\mathrm{F}[2,51]=3.825, \mathrm{p}=.028 ; r=$ .36). As shown in Figure 1, the tendency for MS patients to report more memory failures was inversely related to their level of cognitive impairment. The more cognitively impaired the MS patients were, the lower their scores on the PRMQ. In fact, no significant differences were observed in reporting, between MS patients with moderate-severe cognitive impairment and control subjects on PM and RM errors (post-hoc Tukey test: all p's > $.05)$. In contrast, MS patients with mild cognitive impairment reported significantly more frequent memory errors than control subjects in both PM (post-hoc Tukey: $\mathrm{p}<.001 ; r=.55$ ) and RM (post-hoc Tukey: $\mathrm{p}=.024 ; r=.40$ ).

Analyses of the individual scores obtained on the eight categories of errors revealed significant differences between the groups on four categories: PM short-term self-generated cues $(\mathrm{F}[2,51]=9.50, \mathrm{p}<.001 ; r=.61), \mathrm{PM}$ short-term environmental cues $(\mathrm{F}[2,51]=4.17, \mathrm{p}=.021 ; r=.45)$, PM long-term 


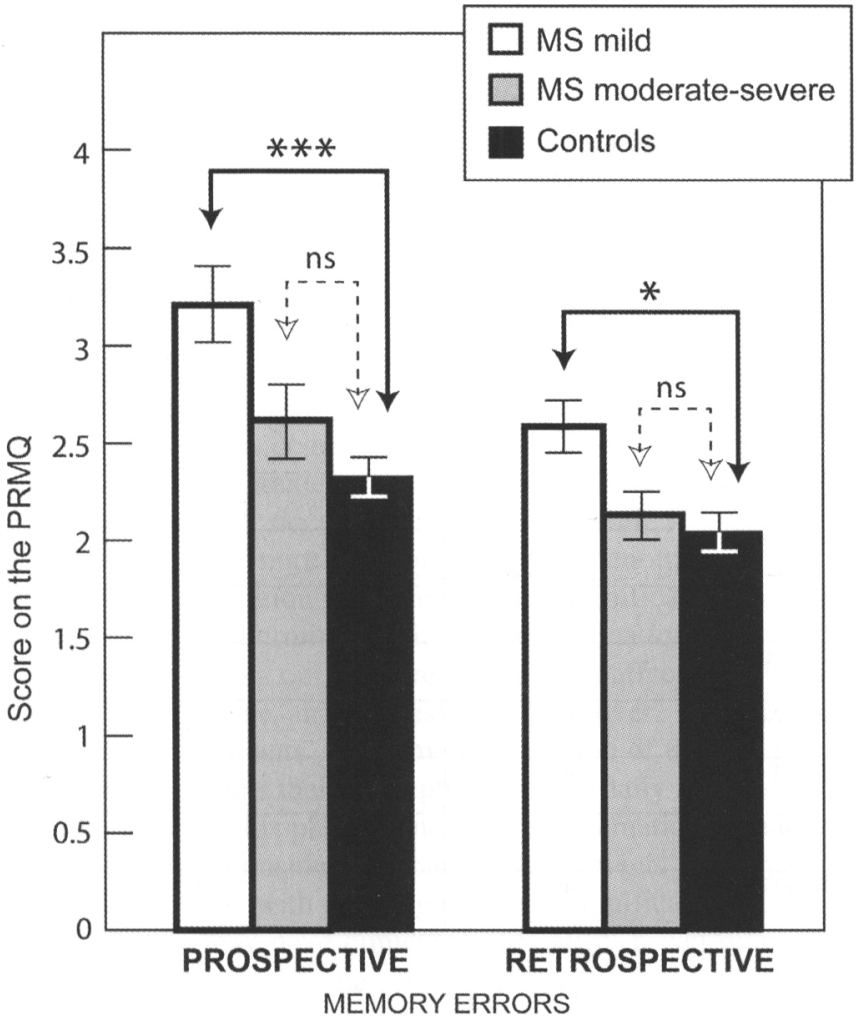

Figure 1: Prospective and retrospective memory errors (score on the $P R M Q$ ) as a function of group (controls, mild cognitive impairment, moderate to severe cognitive impairment). The levels of significance are indicated as follow: ${ }^{*} p<.05,{ }^{*} p<.01$, *** $p<.001$, ns: not significant.

environmental cues $(\mathrm{F}[2,51]=5.27, \mathrm{p}=.008 ; r=.49)$ and finally, $\mathrm{RM}$ short-term self-generated cues $(\mathrm{F}[2,51]=4.81, \mathrm{p}=.012 ; r=$ .45). Post-hoc Tukey tests revealed that MS patients with mild cognitive impairments were reporting significantly more frequent memory errors in those four categories $(p<.05$ in all tests) while control subjects and MS patients with moderatesevere cognitive impairment did not differ ( $p>.10$ in all tests).

Standardized memory tests: because no standardized test of prospective memory was available, the subjective report given by MS patients and control subjects was compared to objective memory performance as assessed by the RAVLT. Data from only 10 control subjects were available but there was no significant differences between those subjects and the other 14 subjects on $\mathrm{PM}(\mathrm{t}[1,22]=.08, \mathrm{p}=.428)$ and $\mathrm{RM}(\mathrm{t}[1,22]=-1.173, \mathrm{p}=$ .253) as measured by the $P R M Q$. As expected, there was a significant effect of group (MS mild, MS moderate-severe, controls) on the total number of words recalled after five trials ( $\mathrm{F}$ $[2,36]=11.11, \mathrm{p}<.001 ; r=.45)$ and for immediate $(\mathrm{F}[2,36]=$ $11.36, \mathrm{p}<.001 ; r=.59)$ and delayed $(\mathrm{F}[2,36]=6.97, \mathrm{p}=.003$; $r=.56)$ recall. The data are presented in Figure 2. Post-hoc Tukey test revealed that although MS patients with mild cognitive impairment and control subjects significantly differed in their subjective judgment of their memory functioning, their performance on the RAVLT was not statistically different for the number of words recalled after five trials $(\mathrm{p}=.786)$, and for immediate $(\mathrm{p}=.157)$ and delayed $(\mathrm{p}=.122)$ recall. In contrast, RAVLT performance in MS patient with moderate-severe cognitive impairment was significantly lower than in normal controls (Post-hoc Tukey test: total recall: $\mathrm{p}=.001, r=.67$; immediate retention: $\mathrm{p}<.001, r=.74$; delayed retention: $\mathrm{p}=$ $.002, r=.63$ ) although these two groups did not differ in their subjective appraisal of their memory functioning.

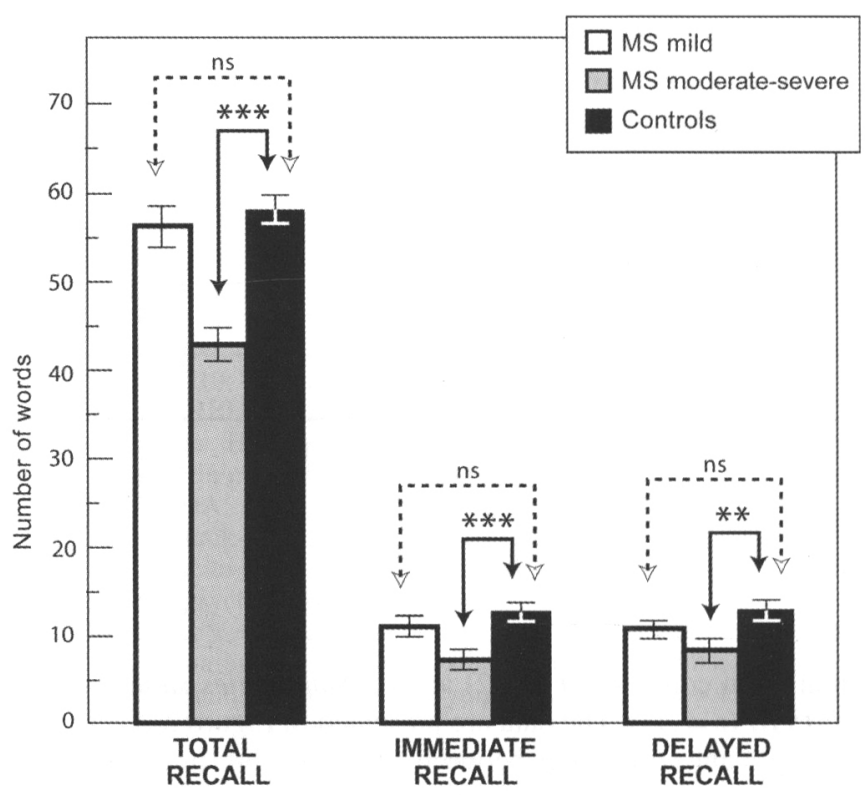

Figure 2: Performance on the Rey Auditory Verbal Learning Test (standardized RM task) as a function of group (controls, mild cognitive impairment, moderate to severe cognitive impairment). The levels of significance are indicated as follow: ${ }^{*} p<.05,{ }^{* *} p<.01,{ }^{* * *} p<.001$, ns: not significant.

Executive function tests: as expected, significant differences between the groups were observed in a composite score of executive functions, $(\mathrm{F}(2,39)=10.69 . \mathrm{p}<.001)$. Post-hoc tests revealed that there was no difference between MS patients with mild cognitive dysfunctions and control subjects on this index whereas significant differences were observed between those subjects (mild and control) and patients with moderate-severe cognitive deficits ( $p<.01$ for all tests). Additional analyses revealed that MS patients with moderate-severe cognitive impairment were deficient compared with the other groups (mild and control: $p<.05$ in all cases) on various measures of executive functions such as the TMT (time on part B- time on part A) $(r=.42)$, Letter fluency $(r=.45)$, errors on the Maze test $(\mathrm{r}=.46)$, number of categories completed on the WCST $(\mathrm{r}=.49)$, number of correct responses on the PASAT $(3 \mathrm{sec})(\mathrm{r}=.46)$, time taken to complete the Zoo Map $(\mathrm{r}=.44)$ and the Stroop 
Table 2: Neuropsychological tests results of participants (MS with mild or moderate/severe cognitive deficit and Controls) Mean (standard deviation)

\begin{tabular}{|c|c|c|c|c|c|}
\hline test & MS mild & MS moderate/severe & Controls & MS mild vs Controls & MS mild vs MS moderate/severe \\
\hline $\begin{array}{c}\text { Trail Making Test } \\
\text { (time: part B - part A) }\end{array}$ & $38.8(18.3)$ & $97.8(88.9)$ & $44.1(30.4)$ & ns & $*$ \\
\hline $\begin{array}{c}\text { Verbal Fluency } \\
\text { (Letter } P, 90 \mathrm{sec} \text { ) } \\
\text { (Fruits and Vegetables, } 90 \mathrm{sec} \text {.) }\end{array}$ & $\begin{array}{l}17.1(6.0) \\
21.8(4.8)\end{array}$ & $\begin{array}{l}11.9(5.4) \\
17.9(5.5)\end{array}$ & $\begin{array}{l}19.4(4.2) \\
24.6(5.1) \\
\end{array}$ & $\begin{array}{l}\text { ns } \\
\text { ns }\end{array}$ & $\begin{array}{c}* \\
\mathrm{~ns}\end{array}$ \\
\hline $\begin{array}{c}\text { Maze test } \\
\text { (number of errors) }\end{array}$ & $2.6(2.1)$ & $7.0(5.6)$ & $2.6(1.8)$ & ns & ** \\
\hline $\begin{array}{c}\text { WCST (128 cards) } \\
\text { (number of categories) }\end{array}$ & $5.6(0.9)$ & $4.6(1.2)$ & $6.0(1.2)$ & ns & * \\
\hline $\begin{array}{c}\text { PASAT }(3 \mathrm{sec}) \\
\text { (number correct } / 60)\end{array}$ & $49.1(10,8)$ & $33.6(17.6)$ & $47.6(9.0)$ & ns & $* *$ \\
\hline $\begin{array}{c}\text { Zoo map } \\
\text { (time in sec.) }\end{array}$ & $132.7(59.3)$ & $206.3(86.6)$ & $145.8(89.6)$ & ns & * \\
\hline $\begin{array}{l}\text { Stroop Inhibition } \\
\text { (time in sec.) }\end{array}$ & $119.4(39.1)$ & $164.7(57.6)$ & $105.6(23.7)$ & ns & $*$ \\
\hline $\begin{array}{c}\text { Similarities (WAIS III) } \\
\text { (scaled score) }\end{array}$ & $11.5(3.0)$ & $9.1(2.0)$ & $13.7(2.9)$ & ns & $*$ \\
\hline $\begin{array}{c}\text { Digit Span (WAIS III) } \\
\text { (scaled score) }\end{array}$ & $11.0(2.3)$ & $8.3(2.9)$ & $9.8(2.0)$ & $\overrightarrow{\mathrm{ns}}$ & * \\
\hline $\begin{array}{c}\text { Comprehension (WAIS III) } \\
\text { (scaled score) }\end{array}$ & $12.4(2.2)$ & $9.3(2.4)$ & $14.0(2.4)$ & ns & $* *$ \\
\hline $\begin{array}{l}\text { Picture Arrangement (WAIS III) } \\
\text { (scaled score) }\end{array}$ & $12.1(3.8)$ & $9.3(3.5)$ & $13.2(4.6)$ & ns & ns \\
\hline $\begin{array}{l}\text { Clock Drawing Test } \\
\text { (score on command } / 10 \text { ) }\end{array}$ & $9.9(0.4)$ & $8.4(1.7)$ & $9.8(0.4)$ & $\mathrm{ns}$ & ** \\
\hline $\begin{array}{l}\text { Bell cancellation test } \\
\text { (time in sec.) }\end{array}$ & $107.7(25.3)$ & $149.3(54.5)$ & $100.0(37.3)$ & ns & * \\
\hline
\end{tabular}

Tukey post-hoc: * $\mathrm{p}<.05, * * \mathrm{p}<.01, * * * \mathrm{p}<.001$

(inhibition condition: $r=.42$ ) and on Similarities subtest of the WAIS III $(r=.43)$. The data are presented in Figure 2. There was a significant correlation between the executive function index and report of PM errors (Pearson $r=.469, p=.009$ ) and $R M$ errors (Pearson $r=.466, p=.01$ ) in MS patients but not in nonclinical controls ( $p>.10$ in all cases). The better the MS group performed on the executive function tests, the more they complained of memory problems. Conversely, the worst they performed on these tests, the less they complained.

$B D I$ : there were no significant differences between patients with mild cognitive dysfunction and patients with moderate severe cognitive dysfunction on the Beck scale of depressive symptoms $(F(1,29)=0.224, p=0.801)$, notwithstanding the fact that we used an adapted version that did not use the somatic symptoms ${ }^{21}$ to calculate the global score $F(1,29)=0,351, p=$ 0.558). There was a correlation between the PM index and the score on the $B D I(r=.409 ; p=0.022$ [two tailed]) which suggests that the overestimation of PM memory problems are at least partially explained by a depressive affect.

\section{Discussion}

Our study shows that the subjective assessment of memory functions in daily life does not adequately reflect objective memory test results. In MS patients with mild cognitive dysfunction, there was a significant overestimation of their memory deficits, while in MS patients with moderate - severe cognitive impairment, a significant underestimation was found. To our knowledge, although a number of studies have shown a lack of correlation between subjective and objective results in MS patients, no studies have reported both overestimation and underestimation of memory deficits in a single study of MS patients. Because of the small number of subjects, these results must be interpreted with caution even though effect size was strong enough to support the relationship between cognitive status and subjective assessment of memory deficits.

The underestimation noted in patients with moderate - severe cognitive impairment was expected and is consistent with another study which reported that up to one third of their patients underestimate their cognitive or functional deficits. ${ }^{14}$ This lack of awareness was observed mainly in patients with executive functions impairment. This was also reported in another study ${ }^{16}$, although the patients were able to adequately judge changes over time in their cognitive status.

Although MS patients with mild cognitive deficits do not differ from controls on objective memory tests results, they tend to overestimate their memory deficits. A possible explanation could be the presence of depressive/anxiety semiology as assessed by the $B D I$ in this group. However, one can question the reliability of the self-reporting of depression symptoms. If these patients are not reliable judges of their cognitive abilities, one cannot presume that they are reliable judges of the symptoms used to diagnose depression.

One can also question the reliability of the answers given on the $P R M Q^{15}$. However, there are two arguments in favor of the reliability of the data. On the one hand, there is the effect size, the strong distinction between the two groups, moderate-severe cognitive deficits versus mild cognitive deficits. The groups 
responded in a coherent fashion as polar opposites. If the tendency would be to give unreliable answers to the questionnaire, there is no explanation for such a consistent pattern of answers, which are more characteristic of their respective clinical groups than of unreliable answers that by definition would tend towards a random distribution of under and overestimation. On the other hand, there is convergence between some of our results and those obtained by others, specifically those concerning patients with severe cognitive deficits. ${ }^{14,17,22-25}$

In order to better understand why MS patients overestimate or underestimate their cognitive deficits, it would be important to add measures of anxiety and fatigue to the list since these symptoms are well documented in MS. As well, a longitudinal study might shed more light on the phenomenon, especially if this error of estimation has some clinical significance. It would be important to determine if this error of estimation is limited to cognitive abilities, or is more pervasive, affecting physical abilities, self-image and self-esteem. Moreover, some authors report that the patients' problem of estimation of their cognitive abilities also affects their perception of their daily functioning ${ }^{14}$. In order to study this phenomenon more systematically, it would be pertinent to consider comparing the patients' judgment of cognitive deficits with the judgment of a significant other ${ }^{26}$. As a discrepancy may have clinical significance, it can be used to justify a more complete neuropsychological evaluation in order to better characterize the abilities and needs of the patient.

These results demonstrate the difficulty of assessing cognitive deficits during a routine clinical evaluation. When there is a reported impact on activities of daily living, on learning, or on working capacities, the opinion of relatives should be sought and interfering factors, such as fatigue should be addressed. If the presumption is confirmed, a proper evaluation should be performed, leading to adapted reparative strategies.

\section{REFERENCES}

1. Achiron A, Barak Y. Cognitive impairment in probable multiple sclerosis. J Neurol Neurosurg Psychiatry. 2003;74:443-6.

2. Chiaravalloti ND, DeLuca J. Cognitive impairment in multiple sclerosis. Lancet Neurol. 2008;7:1139-51.

3. DeSousa EA, Albert RH, Kalman B. Cognitive impairment in multiple sclerosis: A review. Am J Alzheimer Dis Other Demen. 2002;17:23-9.

4. Foong J, Rozewicz L, Quaghebeur G, et al. Executive function in multiple sclerosis: the role of frontal lobe pathology. Brain. 1997;120:15-26.

5. Janculjak D, Mubrin Z, Brinar V, Spilich G. Changes of attention and memory in a group of patients with multiple sclerosis. Clin Neurol Neurosurg. 2002;104:221-7.

6. Rao SM, Leo GJ, Bernardin L, Unverzagt F. Cognitive dysfunction in multiple sclerosis I: frequency, patterns, and prediction. Neurology. 1991;41:685-91.

7. Brassington JC, Marsh NV. Neuropsychological aspects of multiple sclerosis. Neuropsychol Rev. 1998;8(2):43-77.

8. Feinstein A. The neuropsychiatry of multiple sclerosis. Can J Psychiatry. 2004;49(3):157-63.

9. Reuter F, Audoin B, Rico A, Malikova I, Ranjeva JP, Pelletier J. Cognitive Impairment. Rev Neurol. 2009;165:\$113-22.

10. Bravin JH, Kinsella GJ, Ong B, Vowels L. A study of performance of delayed intentions in multiple sclerosis. J Clin Exp Neuropsychol. 2000;22: 418-29.

11. McIntosh-Michaelis SA, Roberts MH, Wilkinson SM, et al. The prevalence of cognitive impairment in a community survey of multiple sclerosis. Br J Clin Psychol. 1991;30:333-48.
12. Rendell PG, Jensen F, Henry JD. Prospective memory in multiple sclerosis. J Int Neuropsychol Soc. 2007;13:410-6.

13. Maor Y, Olmer L, Mozes B. The relationship between objective and subjective impairment in cognitive function among multiple sclerosis patients - the role of depression. Mult Scler. 2001;17 (2):131-5

14. Sherman TE, Rapport LJ, Ryan KA. Awareness of deficit in multiple sclerosis. J Clin Exp Neuropsychol. 2008;30(3):301-11.

15. Smith G, Della Sala S, Logie RH, Maylor EA. Prospective and retrospective memory in normal ageing and dementia: A questionnaire study. Memory. 2000;8(5):311-21.

16. Christodoulou C, Melville P, Scherl WF, et al. Perceived cognitive dysfunction and observed neuropsychological performance: Longitudinal relation in persons with multiple sclerosis. J Int Neuropsychol Soc. 2005;11:614-9.

17. Middleton LS, Denney DR, Lynch SG, Parmenter B. The relationship between perceived and objective cognitive functioning in multiple sclerosis. Arch Clin Neuropsychol. 2006; 21:487-94

18. McDonald WI, Compston A, Edan G, et al. Recommended diagnostic criteria for multiple sclerosis: guidelines from the International Panel on the diagnosis of multiple sclerosis. Ann Neurol. 2001;50:121-7.

19. Kurtzke JF. Rating neurological impairment in multiple sclerosis: An expanded disability status scale (EDSS). Neurology. 1983; $33: 1444-52$.

20. Ouellet J, Scherzer PB, Rouleau I, et al. Assessment of social cognition in patients with multiple sclerosis. J Int Neuropsychol Soc. 2010;16(2):287-96.

21. Benedict RBH, Fishman I, McClellan MM, Bakshi R, WeinstockGuttman B. Validity of the Beck Depression Inventory-Fast Screen in multiple sclerosis. Multiple Sclerosis. 2003;9:393-6.

22. Carone DA, Benedict RH, Munschauer FE 3rd, Fishman I, Weinstuck-Guttman, B. Interpreting patient/informant discrepencies of reported cognitive symptoms in MS. J Int Neuropsychol. Soc. 2005;11(5):574-83.

23. Goverover Y, Chiaravalloti N, DeLuca J. The relationship between self-awareness of neurobehavioral symptoms, cognitive functioning, and emotional symptoms in multiple sclerosis. Mult Scler. 2005;11:203-12.

24. Julian L, Merluzzi NM, Mohr DC. The relationship among depression, subjective cognitive impairment, and neuropsychological performance in multiple sclerosis. Mult Scler. 2007;13:81-6.

25. Marrie RA, Chelune GJ, Miller DM, Cohen A. Subjective cognitive complaints relate to mild impairment of cognition in multiple sclerosis. Mult Scler. 2005;11:69-75.

26. Crawford JR, Henry JD, Ward AL, Blake J. The prospective and retrospective memory questionnaire (PRMQ): Latent structure, normative data and discrepancy analysis for proxy-ratings. Br J Psychol. 2006;45:83-104. 